\title{
ARTICLE
}

\section{Conceptual Art and Aesthetic Ideas}

\author{
Diarmuid Costello \\ University of Warwick, Warwick, UK \\ Email: D.Costello@warwick.ac.uk
}

\begin{abstract}
This paper considers whether Kant's aesthetics withstands the challenge of conceptual art. I begin by looking at two competing views of conceptual art by recent philosophers, before settling on an 'inclusive' view of the form: conceptual art includes both 'strong' and 'weak' non-perceptual art (NPA). I then set out two kinds of conceptual complexity that I argue are implicated by all aesthetic judgements of art (as art) on Kant's view: the concept of art itself, and the idea the work is meant to express (dependent beauty and aesthetic ideas, respectively). I go on to demonstrate the applicability of Kant's aesthetics to conceptual art by considering two works by Lawrence Weiner, which I take to be a work of work of weak and strong NPA respectively.
\end{abstract}

Keywords: aesthetic ideas; conceptual art; non-perceptual art; Lawrence Weiner

This article considers whether Kant's aesthetics withstands the challenge of conceptual art. I take conceptual art rather than some other, more recent, form of contemporary art as my focus because conceptual art is widely taken to be explicitly motivated by hostility towards aesthetic approaches to art. If this is true - and it may not be - one should expect it to offer the stiffest challenge to aesthetic theories of art, Kant's included. Before moving on to the substantive issue, it will help to clarify how I understand 'conceptual art', a category that tends to be employed rather loosely by philosophers - including some working directly on the domain.

\section{Competing conceptions of conceptual art}

Conceptual art can be defined widely or narrowly, both temporally and geographically, depending on whether or not one includes any of its precursor forms or more obvious legacies, and its canonical Western variants or the parallel non-Western developments that only became widely known slightly later. In terms of this broader perspective, I shall adopt a relatively restrictive definition here, certainly by comparison to how the term is typically used in philosophy. But in terms of debates internal to conceptual art, which is a highly contested field - particularly as to who did what, when, where and whether doing so constitutes conceptual art 'proper' - I will adopt a 
relatively permissive definition, so as to avoid reducing conceptual art to the preferred variant of any of its more outspoken exponents. Conceptual artists were involved in a struggle for critical recognition and art-world patronage, and their claims need to be read accordingly. This is true of artists' claims more generally, but it is especially true of conceptual artists' claims, given the nature of this art. ${ }^{1}$ For present purposes I shall bracket these often fractious internal debates and focus on more recent accounts by philosophers, such as Peter Osborne and the co-authored work of Peter Goldie and Elisabeth Schellekens. ${ }^{2}$

Osborne is probably the most art-historically informed philosopher working on conceptual art. Perhaps unsurprisingly, given his underlying Adornian orientation, Osborne presents conceptual art as the product of a series of 'negations' - of the material object, the artistic medium, (good) visual form and established modes of artistic autonomy. Taken together these ideas tend to underpin aesthetic conceptions of art, particularly in more recent modernist incarnations. For this reason, Osborne understands conceptual art as not so much another form of art, on a par with any other such form, as an attempt to transform the very nature of art, as understood by aesthetic theory - a fortiori modernist aesthetics - altogether. (Osborne 2002: 18)

Like art-historical commentators, Osborne divides conceptual art into a number of subgenres. Rather than run through his entire taxonomy here, a few words about the artists he gathers under the headings 'Process, System and Series' and 'Word and Sign' - which include LeWitt and Kosuth respectively - will be sufficient. Osborne presents the former, process-based and systems-oriented, kind of conceptual art as a hybrid genre that tracks the emergence of conceptual art from the minimalist interest in seriality, series and systems. It includes artists, such as Bochner and LeWitt, who Osborne takes to be pushing Donald Judd's minimalist reduction of art to objecthood to the very cusp of art as idea, without ever quite settling on the presentation of ideas themselves as sufficient. Though ideas alone were sufficient according to LeWitt's 'Sentences on Conceptual Art', the work of neither left behind visual presentation altogether, and the extent to which LeWitt equivocates, particularly in 'Paragraphs on Conceptual Art' as to whether conceptual artists are only interested in conception, or both conception and execution, is notable (LeWitt 2000)

Under his latter heading, Osborne includes artists, such as Barry, Weiner and Kosuth, who in various, often conflicting, ways used language to replace or eclipse art's visuality. As Osborne notes, the differences between these artists, often lumped together simply in virtue of their mutual participation in some of the more influential early Seth Siegelaub shows, could be better marked than they are. Among them, only Kosuth claimed to be exclusively focused on the concept of art, in such a way that only his own practice deserved to be called conceptual art 'proper'. This is the standard pose of what Osborne calls 'strong' or 'exclusive' conceptual art, which also includes the early work of Art \& Language. By contrast, Weiner maintained an almost sculptural interest in the empirical investigation of materials and actions, and understood his own 'Statements' in this light. Barry is also still involved, albeit in an attenuated sense, with matter: inert gases are matter in indeterminate form and sound waves remain measurable - unlike thoughts - if not material. So, where Kosuth took himself to be interrogating the concept of art in a manner inspired by the philosophy of language, Barry used language to pick out works made of invisible matter or forms of energy, and Weiner used compact linguistic 'statements' to describe the empirical 
investigation of concrete materials and actions. Each makes use of language, albeit in very different ways.

But what I want to retain from Osborne's division of the field is its underlying nonnormative distinction between the 'weak' or 'inclusive' view of conceptual art held by LeWitt and many others, and the 'strong' or 'exclusive' notion of conceptual art preferred by Kosuth and Art \& Language in particular. ${ }^{3}$ Only the latter, more restrictive variant consisted solely of the self-reflexive investigation of art's concept or definition. This is what Kosuth called 'pure' or 'theoretical' conceptual art, and liked to counterpose pejoratively to 'stylistic' conceptual art: that is, art that has the look of conceptual art, but is compromised by its residual morphological or stylistic commitments.

Peter Goldie and Elisabeth Schellekens's co-authored work, which is the most ambitious attempt to frame a general definition of conceptual art from within the analytic tradition, takes a very different line. ${ }^{4}$ Fundamental to their approach is a distinction between an artistic medium and a (mere) means. In conceptual art, the traditional medium, which would typically be a physical object or set of worked materials, is reduced to a mere means, and ideas become the medium proper. The former may be what enables us to pick out the latter, but it is no longer the work's medium - there is no physical medium in conceptual art. For this reason, whatever object, materials or event allow us access to the ideas that serve as the work's medium, they cannot be the proper focus of appreciative judgement. Viewed from this perspective, the title and photograph documenting a work in Barry's Inert Gas series - in which Barry releases a specific amount of inert gas into the atmosphere - constitute mere means for making these works available, rather than these works' media. Were they its media, it would matter how they are realized, and it does not. ${ }^{5}$ The medium here is an idea, the photographs and title are the means by which the artist grants us access to that idea.

Goldie and Schellekens take this to be true of all conceptual art. But if this were right, bona-fide conceptual art would reduce to a remarkably small subset of what is standardly treated as such, and first order artistic, critical, curatorial practice would be hopelessly confused. Indeed, it is only strictly true of 'strong' conceptual art, its most puritanical form. As such, it is actually something of a minority position within the larger field. Goldie and Schellekens come close to granting this themselves, when they acknowledge that perhaps not all works of conceptual art are fully disembodied or 'dematerialized' after all. Left hanging like this, however, such an admission risks rendering their account stipulative.

Because they understand conceptual art as a whole to entail the irrelevance of material embodiment to artistic value, Goldie and Schellekens are committed to an even stronger perception of the 'ontological challenge' that conceptual art presents for traditional conceptions of art than Osborne. What Osborne presents privatively, as a negation of traditional forms, Goldie and Schellekens present positively, as 'the idea idea', but the upshot is much the same substantively (Osborne 2002: 18-19; Goldie and Schellekens 2007: 55-60). If the idea is now the work, to appreciate the work is to appreciate the idea the work puts forward. The question then becomes: in what ways may ideas be appreciated? Here Goldie and Schellekens make a move than runs directly counter to Osborne: they use the challenge that conceptual art presents to traditional conceptions of art to motivate a form of 'aesthetic idealism' that seeks to recoup conceptual art for aesthetic theory. ${ }^{6}$ If ideas can have aesthetic qualities, and there seems no good reason to deny this - ideas can strike us as elegant 
or incisive, clumsy or ugly - then conceptual art need not be construed as inimical to aesthetic response per se; it need only be construed as hostile to aesthetic response as this is now standardly conceived: that is, as a sensuous or felt response to perceptual form. ${ }^{7}$ This, of course, is precisely the conception of aesthetic response standardly attributed to Kant's aesthetics as a species of formalism in the philosophy of art. The question for us is whether there is anything in Kant's aesthetics that precludes ideas being appreciated in ways that appreciating works of conceptual art aesthetically would seem to require. To demonstrate the applicability of Kant's aesthetics to works of this kind, we need to show that it is possible for us to engage in indeterminate, imaginatively stimulating, ways with the ideas that works of conceptual art present.

My own view, while it has more in common with the inclusivity of Osborne's account than with the exclusivity of Goldie and Schellekens's, is distinct from both: conceptual art is one form of non-perceptual art. 'Non-perceptual art' (NPA), as I conceive it, encompasses both works presented in context of visual art, the perceptible properties of which are entirely irrelevant to their appreciation as art, and works presented in the context of visual art that are not reducible to the sensible properties of what picks them out. In effect, there is a strong and a weak formulation of NPA: strong non-perceptual art (SNPA) denotes works that have no sensible properties, so proper appreciation of such works cannot involve appreciation of the sensible object or event that picks them out; weak non-perceptual art (WNPA), by contrast, denotes works that do possess sensible properties, but which are not exhausted by those properties; so proper appreciation cannot only involve appreciation of such properties. The stiffest challenge to Kant's aesthetics is presented by SNPA rather than WNPA; but because SNPA distinguishes, but does not exhaust, conceptual art, the more permissive conception of conceptual art proposed by Osborne - according to which SNPA would be one subgenre of a more varied general form - is to be preferred. ${ }^{8}$

But if perceptible properties are not the source of SNPA's value as art, what is? The obvious candidate would be the works' semantic properties. If our relation to such properties can be understood aesthetically, then it should in principle be possible to appreciate SNPA aesthetically. But can we do so in ways that Kant's conception of art and aesthetic judgement, more specifically, would encompass? Doing so requires showing that conceptual art supports the kind of imaginative engagement with ideas that promote what Kant calls a 'feeling of life' (Lebensgefühl), a pleasure taken in the enhancement of the subject's own cognitive powers. Demonstrating the applicability of Kant's aesthetics to conceptual art requires making good on this claim.

\section{Conceptual complexity in Kant's aesthetics}

Before that can be done, however, common assumptions about the narrow scope of Kant's aesthetics need to be defused. I begin by drawing attention to two forms of conceptual complexity that - at least arguably - pertain to the aesthetic appreciation of art by definition according to the third Critique: the concept of 'the end' determining what the thing in question is supposed to be (Kant's account of dependent beauty, CPJ §16); and the thematic content or idea that the work in question is supposed 
to express (Kant's theory of aesthetic ideas, CPJ §49). By drawing attention to both, my aim is to show that Kant's aesthetics is not conceptually constrained by any contingent historical features of the art of his own day, and can in principle therefore accommodate forms of art that Kant himself would have had no reason to anticipate, let alone consider.

\section{Dependent beauty}

The most basic claim of the Analytic of the Beautiful is that judgements of taste are non-subsumptive: they do not subsume an object, event or manifold under a concept in virtue of it exhibiting the relevant traits. Instead, aesthetic judgements attest to the feeling to which a given object, event or manifold gives rise in the judge. But if that is correct, the question arises as to how a kind of judgement that does count a concept among its determining grounds - judgements that 'presuppose a concept of the end that determines what the thing should be, hence a concept of its perfection' could still count as aesthetic according to Kant's own theory (CPJ, 5: 230). ${ }^{9}$ To see this, distinguish two ways of judging the same object: the botanist may judge the beauty of a flower freely, abstracting from everything she knows about the function of flowers in attracting bees and thereby securing pollination, or she may judge it dependently, taking account of its function in her judgement of its beauty. In the former case she focuses exclusively on the beauty of the visual array that meets the eye, in the latter case on the fittingness of such an array to a thing with this function. I suggest it is the latter form of judgement that should - at least standardly - apply to works of art on Kant's account. ${ }^{10}$

Kant's claim, in \$16, that not all works of art are dependently beautiful presents an obvious problem for this interpretation. Kant's examples - 'designs à la grecque', 'foliage for borders or on wallpaper' and 'musical fantasias (without a theme)' (CPJ, 5: 229) - suggest that Kant regards non-representational and decorative art as freely beautiful. Kant's thought seems to be that, because such forms of art do not represent anything, we need not judge them in relation to a concept of some end, or associated notion of perfection in the fulfilment of that end, that might otherwise be suggested. Certainly, this is how Kant has been read by a number of influential twentieth-century formalists in art criticism and theory. ${ }^{11}$ This view is put under pressure, however, when Kant grants (in \$45) that in order to judge artistic beauty as artistic beauty we must be aware that it is art that we judge:

In a product of art one must be aware that it is art, and not nature; yet the purposiveness in its form must still seem to be as free from all constraint by arbitrary rules as if were a product of nature. ... art can only be called beautiful if we are aware that it is art and yet it looks to us like nature. (CPJ, 5: 306, my emphasis)

That is, despite the fact that we must know that it is art rather than nature that we judge, it must nonetheless seem as free from the constraint of concepts or rules that might otherwise impede its free appreciation as mere nature. In granting this, Kant acknowledges that we must at least bring the concept of art to be bear on anything judged accordingly, and this could have a wide variety of implications, depending on 
how we understand the concept of art itself. By treating non-representational art as if it were exception to this requirement, formalists try to judge it as though it were free beauty in Kant's sense. But this cannot be right. Consider the differences between a perceptual manifold formed naturally and a similar, even indiscernible, manifold created as art. Only the latter is what Kant would call a 'production through freedom' (\$43): something that, as a product of intentional agency, must be judged in the light of the reasons for which it was made, if it is to be judged accordingly. Abstract and decorative art are no exception: to judge any kind of art freely is to treat it as though it were a product of natural causation, rather than an achievement of artistic agency:

If the object is given as a product of art, and is as such to be declared beautiful, then, since art always presupposes an end in the cause (and its causality), a concept must first be the ground of what the thing is supposed to be, and since the agreement of the manifold in a thing with its inner determination as an end is the perfection of the thing, in judging of the beauty of art the perfection of the thing will also have to be taken into account. (CPJ, 5: 311, my emphasis)

Putting all this together, the implications of Kant's overall position would seem to be: so long as we aspire to judge art as art, not only must we be aware that it is art we are judging; as a product of rational agency, we must take the reasons for which it was made into account. As Kant puts it: 'only production through freedom, i.e. through a capacity for choice that grounds its actions in reason, should be called art' (CPJ, 5: 303). The former is a ground-level commitment pertaining to any judgement of art as such; the latter, while also generalizing across all judgements of art, enables Kant's theory to accommodate the different degrees of thematic complexity that different artworks - abstract art included - may involve. ${ }^{12}$ The upshot is that, while we are in principle free to judge abstract (or any other kind of) art non-dependently, as pure visual array, we cannot judge its beauty as artistic beauty freely, even for Kant. The significance of dependent beauty is in this way to make a given (historically and culturally variable) understanding of art internal to any judgement of artistic beauty on Kant's account.

\section{Aesthetic ideas}

We have seen that judging something beautiful as a 'production through freedom' implicates questions of rational agency to which such judgement must remain responsive. What was the artist trying to achieve? What is the resulting work about? What does it express? Keeping such questions in mind requires judging the work in light of a far more varied set of concepts than simply that of art itself. Characterizing works of art as indirect presentations of 'aesthetic ideas' is Kant's way of addressing such questions, and thereby accounting for art's semantic content:

By an aesthetic idea ... I mean that representation of the imagination that occasions much thinking though without it being possible for any determinate thought, i.e. concept, to be adequate to it ... One readily sees that it is the counterpart (pendant) of an idea of reason, which is, conversely, a concept to which no intuition (representation of the imagination) can be adequate. (CPJ, 5: 314) 
Unlike concepts, what ideas pick out have no empirical conditions of application, so cannot constitute genuine objects of knowledge for finite rational beings. Despite this, they retain an action-guiding, regulative function: merely aspiring to act morally, for example, requires that we act under the idea of freedom - irrespective of whether we are in fact free, or can know that we are. But if ideas have no empirical conditions of application, how could they be given sensible embodiment in art? Kant's account of aesthetic ideas is meant to explain this, by clarifying what is distinctive both about (i) the content of works of art and (ii) how works of art are obliged to embody or express such content as a result. Kant's conception of the former is disjunctive: either works of art present ideas the objects of which can be encountered in experience (love, envy, death, fortitude), but do so with a fullness that experience itself rarely affords; or they present super-sensible ideas (immortality, God, freedom, the soul) the objects of which cannot, in principle, be encountered in experience. In effect, Kant offers a weaker (or more inclusive) and a stronger (or more exclusive) formulation of what works of art express, and that he does is just as well: given that most works of art do not in fact present ideas in the stronger, more exclusive sense, it would render Kant's theory indefensibly stipulative were he to insist on the stronger formulation for all works of art. ${ }^{13}$

So much for what is distinctive about the content of works of art, according to Kant: how are works of art able to express such content? Given that Kant takes ideas to be distinguished from concepts by the fact that they cannot adequately be presented to intuition, works of art must of necessity present such ideas indirectly. To explain how this is possible, Kant distinguishes between the 'logical' and 'aesthetic' attributes of an idea: an idea's logical attributes would be those traits in virtue of the fulfilment of which the idea in question is applicable; an idea's aesthetic attributes, by contrast, would be an indirect or figurative presentation of those same attributes by means of 'supplementary representations of the imagination' that 'express only the implications connected with [an idea] and its affinity with others' (CPJ, 5: 315). This makes Kant's thought sound much more obscure than it is. Take Kant's own example: 'Jupiter's eagle with the lightning in its claws' presents the idea of God's majesty figuratively, by means of an image (CPJ, 5: 315). In the case of 'God's majesty', the idea's logical attributes would be omniscience, omnipotence and so on. While such attributes cannot be exhaustively presented in intuition by finite rational beings, the image of Jupiter's eagle can, and when one reflects on the presentation of a being powerful and otherworldly enough to grip a bolt of lightning in its talons, one is on the way to imagining the awe-inspiring nature of God's majesty. In sum, aesthetic ideas constitute a kind of metaphor, visual or otherwise. Here: see God's majesty in the light of the wealth of thoughts provoked by Jupiter's eagle.

The indirection necessitated by presenting rational ideas in sensible form has an additional benefit on Kant's account: because it prompts imagination to spread over the rich seam of images, thoughts and associations triggered by a given presentation, the indirect presentation of ideas 'aesthetically expands' (ästhetisch erweitet) the ideas thereby presented. As a result, works of art 'animate' or 'enliven' (beleben) the mind, freeing imagination from the subservient role of merely schematizing concepts of understanding, by allowing it to roam widely over an array of related concepts and presentations that provide more material for reflection, and in so doing provoke more thought, than a direct presentation could afford. In sum: 
[aesthetic attributes] give the imagination cause to spread itself over a multitude of related presentations, which let one think more than one can express in a concept determined by words; they yield (geben) an aesthetic idea, which serves that idea of reason instead of logical presentation, although really only to animate the mind by opening up for it the prospect of an immeasurable field of related presentations. (CPJ, 5: 315)

\section{Conceptual art and aesthetic ideas: a case study}

The question is whether this understanding of works of art as indirect - typically metaphorical - presentations of ideas that cannot be fully presented in intuition accommodates conceptual art. ${ }^{14}$ Recall the competing conceptions of conceptual art discussed in section 1 . The view I proposed there, according to which SNPA distinguishes but does not exhaust conceptual art, generates a four-fold taxonomy: (i) WNPA that is not in fact conceptual art, such as Marcel Duchamp's Fountain (1917) or Robert Rauschenberg's Erased de Kooning (1953), although it is widely treated as such by analytic philosophers of art; (ii) WNPA that is conceptual art, such as Lawrence Weiner's A 36" x 36" REMOVAL TO THE LATHING OR SUPPORT WALL OF PLASTER OR WALLBOARD FROM A WALL (1968) or Art \& Language's Index 01 (1972); (iii) SNPA that is conceptual art, such as Weiner's THE ARCTIC CIRCLE SHATTERED (1969) or Robert Barry's All the things I know but which I am not at the moment thinking - 1:36pm; June 5, 1969 (1969); and (iv) SNPA that is not conceptual art, which I take to include many (non-avant-garde) works of literature, and all works of literature in translation. Whether the latter also includes works of art is an interesting question; the answer will be no if only conceptual art can be SNPA, but not if there is SNPA that is not conceptual art. I wish to remain neutral on this question here.

I have defended this taxonomy elsewhere..$^{15}$ For present purposes I focus on the works by Lawrence Weiner, the better to bring out some differences between WNPA and SNPA, and to demonstrate that Kant's theory of art can accommodate both. ${ }^{16}$ Some context will be helpful. Weiner started out as a painter, and the paintings of relevance to the first of the two works I want to discuss are the Removal Paintings from the mid to late 1960s. These are reductive, hard-edged abstractions, typically comprising several bands of spray-painted colour but occasionally monochrome, with one or more rectangular notches removed from their corners to generate irregularly shaped canvases. Not only the colours used and the intensity of those colours, but also the size of both the paintings and the removals from them, were determined by the works' recipients. These paintings, which Weiner discontinued in spring 1968, precede A 36" $\times 36$ " REMOVAL TO THE LATHING OR SUPPORT WALL OF PLASTER OR WALLBOARD FROM A WALL (1968). Calling the latter a work of weak rather than strong NPA may seem odd, in view of the famous 'Statement of Intent' (1969) that oriented Weiner's production once he gave up painting in 1968. Central to this statement was the idea that a work may, but need not be physically realized, reflecting Weiner's belief that the work exists as soon as the words that pick it out are made public:

1. The artist may construct the work

2. The work may be fabricated

3. The work need not be built 
Each being equal and consistent with the intent of the artist, the decision as to condition rests with the receiver upon the occasion of receivership. (Weiner 1969: n.p.)

The inspiration for this statement, according to Weiner, was what happened to an important transitional work that he exhibited in Siegelaub's group show Hay, Mesh, String at Windham College, Vermont (May 1968). Staples, Stakes, Twine and Turf, as it was originally titled, comprised a $30 \times 21 \mathrm{~m}$ grid marked out by thirty-four wooden stakes strung together with twine, with a smaller rectangle removed from one corner of the larger rectangle, much like the 'Removal Paintings'. It was installed on a lawn between two student dorms, and soon vandalized by students wishing to reclaim the space for touch football. On seeing the result Weiner concluded that it did not matter, since the work itself remained undamaged. When republished in Weiner's book Statements (1968) the work became 'A series of stakes set in the ground at regular intervals to form a rectangle with twine strung from stake to stake to demark a grid a rectangle removed from this rectangle' (1968), a formulation consistent with, but not exhausted by, its original incarnation (Weiner 1968: n.p.). In its reconfigured form, in common with all Weiner's works released as 'Statements', the work exists irrespective of whether or not it is built. Prima facie, this looks like as good an illustration of Goldie and Schellekens' 'idea idea,' as one might hope for: if the work can exist independently of being built, then no physical properties of any particular installation can be essential to its nature. As Weiner subsequently clarified: 'there is no correct way to construct the piece as there is no incorrect way to construct it. If the piece is built it constitutes not how the piece looks but only how it could look' (Weiner, in Lippard 1997: 74). But one must be attentive to the differences between individual works when considering Weiner's corpus in light of this general statement, as 36 " $\times 36$ " SQUARE REMOVAL (Figure 1) makes clear.

According to the basic logic of Weiner's post-painting corpus, a work like this exists as soon as the words that pick it out are made public, irrespective of whether it is ever actually built. Conversely, the work may be built (or, perhaps better, installed) innumerable times on a variety of different, but compliant, surfaces and remain the same work. But distinguish the question of the work's identity which, according to the parameters established by Weiner's mature practice does not require instantiation, from the question of what is required to appreciate such a work. Could one possess a full, or even adequate, appreciation of A 36" $\times 36$ " SQUARE REMOVAL without seeing it installed? I think not: much like Sol LeWitt's instruction-based work, one learns a great deal from seeing such a work installed. Indeed, not only can one not have an adequate appreciation of the work without seeing it installed, one will gain a much richer appreciation from seeing it installed on a variety of surfaces. So what do we learn from seeing this work installed?

In the iconic photographs of its early installations (in the McLendon Building, NYC, for Siegelaub's January 5-31, 1969 (1969) or Kunsthalle, Berne for Harald Szeeman's Live in Your Head. When Attitudes Become Form: Works - Concepts - Processes - Situations Information (March-April 1969)) one sees the absence or refusal of painting itself. This is the moment in Weiner's oeuvre at which the removal of painting as such and in its entirety, and not merely a part thereof (a removal from an individual painting) 


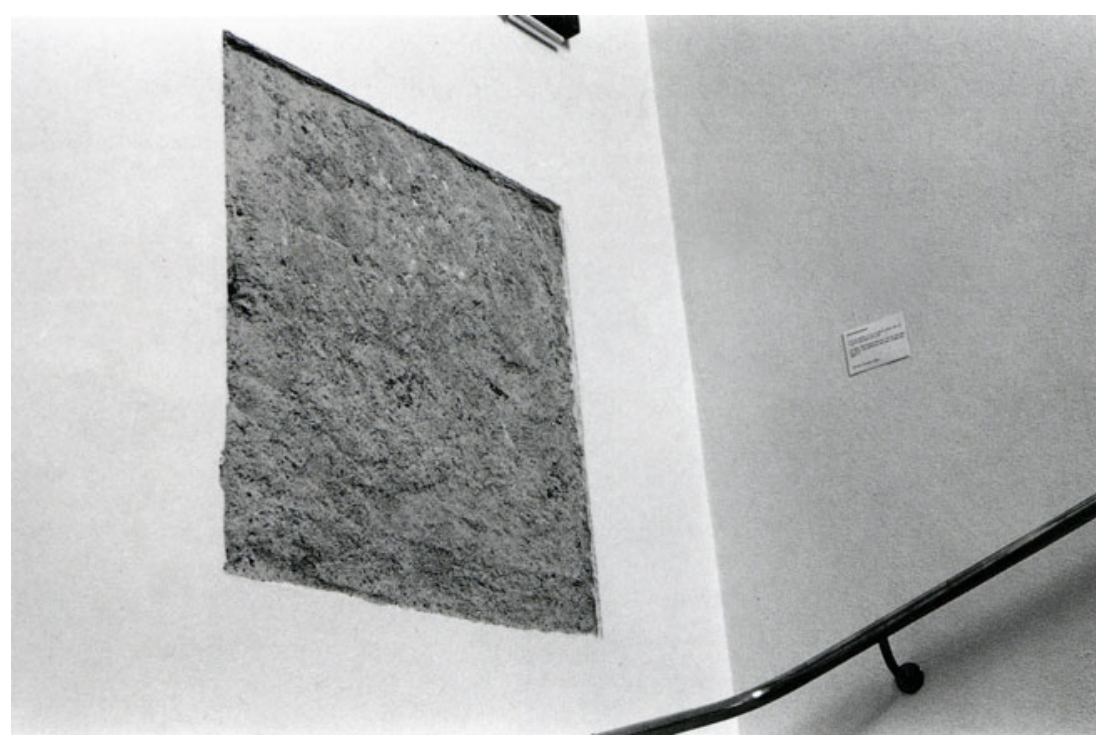

Figure I. Lawrence Weiner, A 36" x 36" REMOVAL TO THE LATHING OR SUPPORT WALL OF PLASTER OR WALLBOARD FROM A WALL, 1968, Works \& Reconstructions, Kunsthalle, Berne, Switzerland, 1983. ( 2021 Lawrence Weiner / DACS, London.

is enacted. Once the top layer of plaster, wallboard or similar is removed to reveal the rougher, ungraded surface of the wall below, one sees an after-image or negative of the 'last painting', the painting to end all painting, that the oeuvre of so many firstgeneration conceptual artists either enacts or implies prior to leaving painting behind altogether. ${ }^{17}$ Even the uneven edge created by removing the plaster calls to mind, in negative form, the facture that roughens the edges of a thickly worked painting. What one sees, in effect, is the absence of the painting that Weiner has refused to paint.

But if the work's significance as a kind of pittura negativa remains hidden until one sees it installed, the properties of its material instantiation cannot be mere means; if they significantly shape our understanding of the idea the work embodies - that of the end of painting - they must be internal to the work itself, which can therefore only be weakly, rather than strongly, non-perceptual. As Weiner's notebooks from the time make clear, the work comprises both 'language + the materials referred to', and not merely the former. What I have just drawn attention to in interpreting this work are, in Kant's terms, the 'aesthetic attributes' through which A 36" × 36" SQUARE REMOVAL indirectly communicates the idea of the end of painting. This is something that could only ever be an idea, given that it could not be exhaustively presented to intuition by, say, Weiner simply giving up painting. It is a mark of Weiner's 'genius' not in the everyday sense, but in Kant's sense - to have hit upon an indirect means of presenting what cannot be directly presented despite this:

Genius ... consists in the happy relation which no science can teach and no diligence learn, of finding ideas for a given concept on the one hand and on the 
other hitting upon the expression for these, through which the subjective disposition of the mind that is thereby produced, as an accompaniment of a concept, can be communicated to others. ... to express what is unnameable in the mental state in the case of a certain representation and to make it universally communicable ... requires a faculty for apprehending the rapidly passing play of the imagination and unifying it into a concept ... which can be communicated without the constraint of rules. (CPJ, 5: 317)

Kant's formulation here may be tortuous, but his thought is straightforward. Recall the remarks from $\$ 49$ cited earlier, to the effect that a work's aesthetic attributes 'yield' (geben) an aesthetic idea, the proper function of which is to 'animate' (beleben) the mind of their recipient. Genius is now said to consist in the ability not only 'to find ideas for a given concept' but, more particularly, to 'hit upon ways of expressing these ideas' capable of 'communicating to others' the 'subjective disposition of mind' that accompanies them. These remarks show Kant's theory of artistic creation to be a species of expressionism: the liberation of the recipient's imagination from its standard function of schematizing concepts of the understanding - the hallmark of aesthetic reflective judgement more generally - is achieved through the genius's ability to 'apprehend the rapidly passing play of the imagination and unify it into a concept ... which can be communicated without the constraint of rules'. ${ }^{18}$ So conceived, genius picks out the capacity to render the specific attunement of imagination and understanding occasioned by a particular idea communicable, by embodying its play in the unified organization of aesthetic attributes used to indirectly communicate the work's theme. What Kirk Pillow has called the 'fulfilled aesthetic idea' would be the feeling of cognitive enhancement that such embodiment triggers in the work's appreciator by their appreciation of the work (Pillow 2001: 200ff.).

My second example should help to make this clear. Unlike A 36" × 36" SQUARE REMOVAL, THE ARCTIC CIRCLE SHATTERED is a work of strong NPA (Figures 2 and 3). So what makes the difference? Here I depart from Weiner. Weiner believes not only that this work can be instantiated, but that he has in fact instantiated it. I believe he is mistaken about this: Weiner, I suggest, misconstrues the implications of his own work in this case. In 'Art within the Arctic Circle' Lucy Lippard includes some very underwhelming photographs of Weiner purporting to instantiate this work; the photographs and text document Weiner scoring the surface of a rock by shooting it with .22 rifle. ${ }^{19}$ What Weiner has thereby instantiated is a work that might have been called A RIFLE DISCHARGED IN AN OPEN SPACE Or A ROCK FIRED UPON, or some such; what he has not thereby instantiated is a work titled THE ARCTIC CIRCLE SHATTERED.

Why not? 'The Arctic Circle' is a cartographic abstraction. It denotes the virtual line generated by joining a series of points on the Earth's surface; this line picks out the southern-most limit of the Arctic region (approximately 66 degrees 33 minutes north of the Equator), which fluctuates slightly in line with the Earth's axial tilt relative to the sun, above which the sun viewed from sea level does not set on the summer solstice or rise on the winter solstice. As an abstraction, the Arctic Circle cannot be shattered: abstractions can be undermined, shown to be incoherent or reductive, to misrepresent reality, to have unwanted implications and the like. But they cannot be 'shattered', if this is taken to mean broken into many smaller 


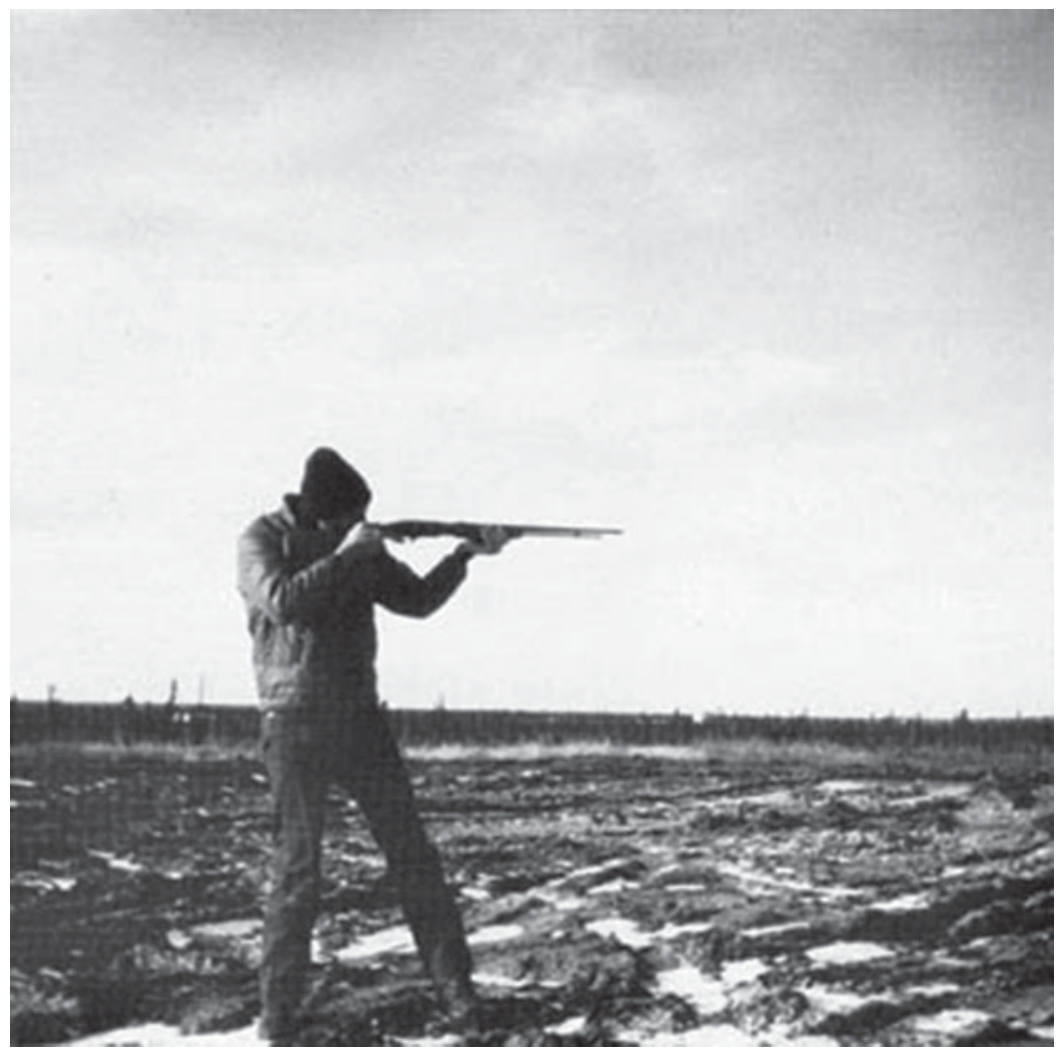

Figure 2. Lawrence Weiner, THE ARCTIC CIRCLE SHATTERED, 1969, sponsored by the Edmonton Art Gallery, Alberta, Canada, for the exhibition Place and Process - Arctic Trip, 1969. (C 202I Lawrence Weiner / DACS, London. Photograph: Lucy Lippard.

Figure 3. Lawrence Weiner, THE ARCTIC CIRCLE SHATTERED, 1969, sponsored by the Edmonton Art Gallery, Alberta, Canada, for the exhibition Place and Process - Arctic Trip, 1969. (c) 2021 Lawrence Weiner I DACS, London. Photograph: Lucy Lippard.

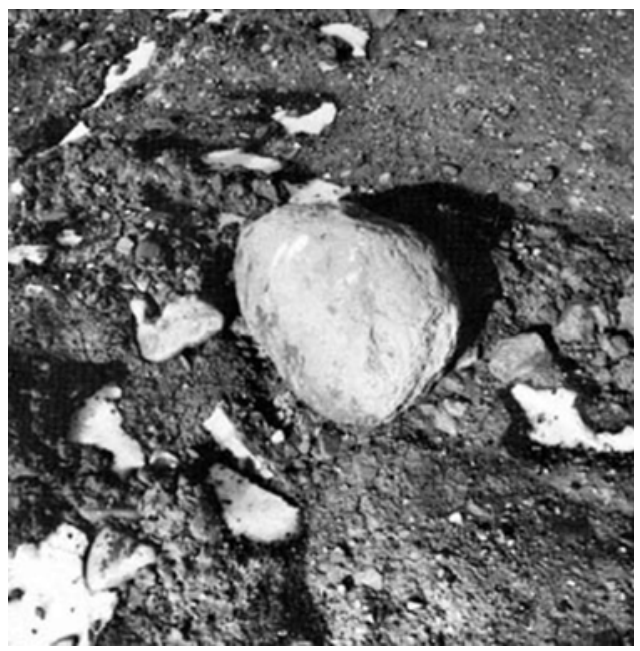


pieces in the way that physical objects can. As I understand it, a work that invites us to entertain the prospect of an abstraction 'shattered' could not be instantiated.

By inviting us to imagine a cartographic abstraction shattered as if it were physically embodied, the work invites us to entertain a category mistake of sorts; the Earth's surface may be shattered in part or in whole - Weiner's earliest works involved detonating explosives in the desert scrub - but an abstraction cannot be. Qua abstraction, it is not in the class of material entities that could be so shattered, unlike Weiner's underwhelming rock. But just what is it that we are being asked to imagine, in entertaining a category mistake of this sort? It is impossible to say definitively or exhaustively, and that it is is to the point. Is it an end to mapping and, assuming mapping to be a distinctly human activity, an end to the imposition of human order on the Earth? If so, this might entail imagining either the idea of an end to humanity, or of humanity's inhabitation of the Earth. Or is it - to adopt a more planetary perspective - the end of our solar system itself and, so too, the Arctic Circle as an index of the Earth's relation to its sun, with the gradual decay of our Sun? These are not ideas that could be presented to intuition in sensible form. Or considered more concretely, in light of contemporary awareness of the climate catastrophe, are we being asked to imagine the ramifying effects of global warming: melting polar ice caps and rising sea levels; the release of greenhouse gases currently trapped in the Arctic permafrost; the slowing of the Gulf Stream? While these interpretations, being in competition, cannot at all be both definitive and correct, engaging with the work aesthetically explicitly does not require us to choose between them. Indeed, prompting imagination to range over such a rich and, in principle, inexhaustible seam of associations and possible interpretations is just what one would expect any successful work to do, on Kant's account of works of art as expressions of aesthetic ideas: that is, 'representation[s] of the imagination associated with a given concept, which [are] combined with such a manifold of partial representations in the free use of the imagination that no expression designating a determinate concept can be found for [them]' (CPJ, 5: 316). Conceptual art is no exception.

\section{The question reconsidered}

I have focused here on making a positive case for the applicability of Kant's account of aesthetic ideas to the kinds of conceptual art typically regarded as the stiffest challenge to aesthetic theories of art. In doing so I have set aside a number of worries: whether Kant is committed, theoretically, to a representational theory of art (\$48); the thorny question of how to understand Kant's remarks on design (\$14) and whether anything in his broader theory requires such a restrictive formalism and, finally, whether Kant is committed to a perceptual theory of art. I have addressed each of these questions elsewhere (Costello 2013); but I will say a word in closing about the last, since this will seem the most worrisome for the extension of Kant's theory to works of art that, in the case of SNPA, I have defined as possessing no perceptual features whatsoever.

However provisional, Kant's division of the arts (\$51) into the 'art of speech, pictorial art, and the art of the play of sensations' makes clear that Kant took himself to be providing a general theory of art - a theory as readily applicable to music or poetry as it is to painting and the plastic arts (CPJ, 5: 321). The terms in which 
Kant discusses poetry, in particular, as an art of non-sensible 'representations of the imagination, which are evoked through words' are instructive here (CPJ, 5: 321-2). Nothing in the aesthetic appreciation of poetry, as Kant presents it, requires taking pleasure in the perceptual manifold through which we access a work of poetry. But if the way in which poems are able to stimulate the imagination without requiring presentation in sensible intuition is accommodated by Kant's theory - Kant even presents poetry as the art form in which our capacity for aesthetic ideas is exercised to the greatest extent - then so too is SNPA. ${ }^{20}$ Appealing to Kant's remarks on the aesthetic appreciation of poetry does of course have the effect of rendering SNPA an 'art of speech' - an art of 'word' or 'thought' rather than 'gesture' or 'intuition' - and WNPA, a more conventional hybrid of the two on Kant's taxonomy.

I welcome this conclusion. Not only would it be anachronistic to expect Kant's theory to make room for works with no perceptible properties relevant to their appreciation within the pictorial arts, it seems entirely fitting: it captures the respects in which SNPA unlike WNPA - contrary to Goldie and Schellekens's attempt to generalize the 'idea idea' - remains an extreme position, a limit case even within the domain of conceptual art. SNPA is a kind of art that relies in large part for its effects on frustrating the expectations generated by its standard contexts of dissemination and display. Kant's theory, it turns out, gets this right. ${ }^{21}$

\section{Notes}

1 Given the conception- rather than execution-driven nature of much of this work, if artists claim to have conceived of works before they had the means to execute them, they thereby claim to have realized these works in the respect that matters, with predictable implications for conflicting claims as to precedence and priority.

2 For a fuller treatment that also considers influential artists, first-generation curator-facilitators and art historians, see Costello forthcoming: chapter 7.

3 'I shall refer to those who advocate an expansive, empirically diverse and historically inclusive use of the term "Conceptual Art" (such as Sol LeWitt) as inclusive or weak Conceptualists. I shall call those championing more restricted, analytically focused and explicitly philosophical definitions (such as Kosuth and Art \& Language) exclusive or strong Conceptualists' (Osborne, 1999: 48-9).

4 Goldie and Schellekens 2007, 2010; Schellekens 2007.

5 This is more contentious than Goldie and Schellekens appear to realize: without argument, one has not shown that the ostentatiously cack-handed, amateurish and 'deskilled' forms of photography practised by conceptual artists, learning productively from Ed Ruscha's books, was not internal to their works' assault on aesthetic conceptions of art that value good form. And if that is true, its ugliness is, in Arthur Danto's terms, 'internal' to its meaning as art.

6 I am abstracting here from Goldie and Schellekens' claim that conceptual art, for all its philosophical interest, nonetheless fails to satisfy the 'deep human needs' that art satisfies. Accepting that this is a failure of conceptual art requires subscribing to a normative notion of art's function in need of explicit defence: faulting conceptual art for failing to provide what it refuses to provide, as part of a broader counter-culture that took itself to have good reason to reject the traditional solaces of art, is to beg the question against it. See Lippard 1997: vii-xxii.

7 Whether this now standard conception genuinely captures the 'traditional' conception is contentious. On its non-applicability to Hutcheson, see Shelley 2003: 375-8.

8 For a fuller account, see Costello 2013.

9 Parenthetical references to Kant's writings give the volume and page number(s) of the Royal Prussian Academy edition (Kants gesammelte Schriften), which are included in the margins of the translations. English translations are from the Cambridge Edition of the Works of Immanuel Kant. CPJ = Critique of the Power of Judgement (Kant 2000). 
10 Precisely how the two elements of a judgement of dependent beauty, combining a judgement of taste with a judgement of perfection, are related is much debated. For my purposes it is not necessary to take a position on this here. For an overview of 'external', 'internal' and 'conjunctive' interpretations, see Guyer 2002.

11 E.g. Greenberg, 1999.

12 Take Barnet Newman's breakthrough 'zip' painting of 1948, Onement 1, comprising a roughly brushed line of cadmium red light bisecting an indeterminate dark background. This is widely interpreted as a representation of the idea of creation ex nihilo (Genesis 1:1-5): 'In the beginning God created the heavens and the earth. Now the earth was formless and empty, darkness was over the surface of the deep, and the Spirit of God was hovering over the waters. And God said, "Let there be light," and there was light. God saw that the light was good, and he separated the light from the darkness. God called the light "day," and the darkness he called "night." And there was evening, and there was morning - the first day.' It is hard to imagine a more sublime idea predicated of a more minimal abstract image.

13 For a broadly similar view, see Matherne 2013.

14 On the metaphorical dimension of Kant's theory, see Costello 2012; Pillow 2001.

15 See Costello 2013.

16 The differences between WNPA and SNPA can be subtle. Weiner's MANY COLORED OBJECTS PLACED SIDE BY SIDE TO FORM A ROW OF MANY COLORED OBJECTS (1979), for example, looks like SNPA but turns out, on closer inspection, to be WNPA.

17 Many conceptual artists started out as painters, and the lingering orientation of their work to the wall reflects this. If minimalists such as Donald Judd pushed the so-called 'modernist reduction' beyond the point at which Greenberg would have seen it halted, such that art tips over into objecthood, conceptual artists such Weiner are widely taken to have pushed its reductive logic beyond the bounds of objecthood. See de Duve 1996: 199-279.

18 On the relation between Kant's expressionism and formalism, see Guyer 1977; Rogerson 1986: 156-65; Allison 2001: 271-301.

19 Lippard 1969-70. The article documents a trip she organized for several artists to make work for 'Place and Process', an exhibition at the Edmonton Art Gallery, Fall 1969). See: http://ccca.concordia. $\mathrm{ca} /$ resources/searches/event_detail.html?languagePref=en\&vk=6940

20 See Kant, CPJ, 5: 314. It is important to keep in mind that what Kant meant by 'poetry' is much broader than what would be meant today. Given that Kant divides the literary arts as a whole between poetry and oratory, the scope of 'poetry' for Kant would be closer to the scope of 'literature' today.

21 This article was given at the 'Kant, Aesthetics and Contemporary Art' Conference at the Cardiff University 23-4 October, 2020. I thank the organizers and audience for their helpful comments.

\section{References}

Allison, Henry E. (2001) Kant's Theory of Taste. Cambridge: Cambridge University Press.

Costello, Diarmuid (2012) ‘Danto and Kant: Together at Last?'. In Mark Rollins (ed.), Danto and his Critics. 2nd edn (Oxford: Wiley-Blackwell), 153-71.

(2013) 'Kant and the Problem of Strong Non-Perceptual Art'. British Journal of Aesthetics, 53(3), 277-98.

- Aesthetics After Modernism. forthcoming.

De Duve, Thierry (1996) Kant After Duchamp. Cambridge, MA: MIT Press.

Goldie, Peter and Schellekens, Elisabeth (2007) Philosophy and Conceptual Art. Oxford: Oxford University Press.

- (2010) Who's Afraid of Conceptual Art? New York: Routledge.

Greenberg, Clement (1999) Homemade Esthetics: Observations on Art and Taste. New York: Oxford University Press.

Guyer, Paul (1977) 'Formalism and the Theory of Expression in Kant's Aesthetics'. Kant-Studien, 68(1-4), 46-70.

(2002) 'Free and Dependent Beauty: A Modest Proposal'. British Journal of Aesthetics, 42(4), 357-66. 
LeWitt, Sol (2000) 'Sentences on Conceptual Art' and 'Paragraphs on Conceptual Art'. In Alexander Alberro and Blake Stimson (eds), Conceptual Art: A Critical Anthology (Cambridge, MA: MIT Press), 12-16, 106-8.

Lippard, Lucy (1969-70) 'Art within the Arctic Circle'. The Hudson Review, 22(4), 665-74.

- (1997) Six Years: The Dematerialization of the Art Object from 1966-1972. Berkeley, CA: University of California Press.

Matherne, Samantha (2013) 'The Inclusive Interpretation of Kant's Aesthetic Ideas'. British Journal of Aesthetics, 53(1), 21-39.

Osborne, Peter (1999) 'Conceptual and/as Philosophy'. In Michael Newman and Jon Bird (eds), Rewriting Conceptual Art (London: Reaktion Books), 47-65.

- (2002) Conceptual Art. London: Phaidon.

Pillow, Kirk (2001) 'Jupiter's Eagle and the Despot's Hand Mill: Two Views of Metaphor in Kant'. Journal of Aesthetics and Art Criticism, 59(2), 193-209.

Rogerson, Kenneth (1986) Kant's Aesthetics: The Roles of Form and Expression. New York: University Press of America.

Schellekens, Elisabeth (2007) 'Conceptual Art'. Stanford Encyclopedia of Philosophy. https://plato.stanford. edu/entries/conceptual-art/.

Shelley, James (2003) 'The Problem of Non-Perceptual Art'. British Journal of Aesthetics, 43(4), 363-78.

Weiner, Lawrence (1968) Statements. New York: Seth Siegelaub/Louis Kellner Foundation.

_ (1969) 'Statement of Intent'. In Seth Siegelaub, January 5-31, 1969, exh. cat. (New York: Seth Siegelaub), unpaginated.

Cite this article: Costello, D. (2021). Conceptual Art and Aesthetic Ideas. Kantian Review 26, 603-618. https://doi.org/10.1017/S1369415421000388 